\title{
Airborne spread and infection of a novel swine-origin influenza $A(\mathrm{H} 1 \mathrm{~N} 1)$ virus
}

\author{
Hongna Zhang ${ }^{1,2,3 \dagger}$, Xin Li ${ }^{1 \dagger}$, Ruihua Ma ${ }^{1,4}$, Xiaoxia Li ${ }^{1,5}$, Yufa Zhou ${ }^{1,7}$, Hongliang Dong ${ }^{1}$, Xinxian $\mathrm{Li}^{1}$, Qinglei Li ${ }^{1}$, \\ Mingliang Zhang ${ }^{1}$, Zhihao Liu ${ }^{1}$, Baozhi Wei ${ }^{1}$, Mingchao Cui ${ }^{1}$, Hao Wang ${ }^{1}$, Jing Gao ${ }^{1}$, Huili Yang ${ }^{1,6}$, Peiqiang Hou ${ }^{1,6}$, \\ Zengmin Miao ${ }^{1,5^{*}}$ and Tongjie Chai ${ }^{i^{*}}$
}

\begin{abstract}
Background: The novel swine-origin influenza A (H1N1) virus (S-O 2009 IV) can cause respiratory infectious diseases in humans and pigs, but there are few studies investigating the airborne spread of the virus. In January 2011, a swine-origin $\mathrm{H} 1 \mathrm{~N} 1$ epidemic emerged in eastern China that rapidly spread to neighboring farms, likely by aerosols carried by the wind.

Methods: In this study, quantitative reverse transcription polymerase chain reaction (RT-PCR) was used to detect viruses in air samples from pig farms. Based on two aerosol infection models (Pig and guinea pig), we evaluated aerosol transmission and infection of the novel S-O 2009 IV isolate.

Results: Three novel S-O 2009 IV were isolated from the diseased pig. The positive rate and viral loads of air samples were $26.1 \%$ and $3.14-5.72 \log _{10}$ copies $/ \mathrm{m}^{3}$ air, respectively. In both pig and guinea pig infection models, the isolate (A/swine/Shandong/07/2011) was capable of forming aerosols and infected experimental animals at a range of 2.0-4.2 $\mathrm{m}$ by aerosols, but aerosol route was less efficient than direct contact.
\end{abstract}

Conclusions: The results indicated that S-O 2009 IV is able to be aerosolized by infected animals and to be transmitted to susceptible animals by airborne routes.

Keywords: S-O 2009 IV, Epidemic, Airborne transmission, Pig, Guinea pig

\section{Introduction}

In April 2009, swine-origin 2009 A (H1N1) influenza viruses (S-O 2009 IV) were found in Mexico and the United States for the first time, and quickly spread throughout the world, presenting a significant threat to public health [1,2]. S-O 2009 IV is a novel triplereassortant influenza virus derived from porcine, human, and avian influenza viruses. Different from seasonal influenza viruses, humans lack immunity to this new virus, and thus the virus quickly caused a pandemic [2-5]. As of March 21, 2010, the World Health Organization (WHO) reported that 213 countries or regions were affected and the number of deaths was at least 16,931 people [6].

\footnotetext{
*Correspondence: zengminmiao@126.com; chaitj117@163.com

${ }^{\dagger}$ Equal contributors

${ }^{1}$ College of Animal Science and Veterinary Medicine, Shandong Agricultural University, Daizong Street 61, Tai'an 271018, China

${ }^{5}$ Taishan Medical University, Tai'an, China

Full list of author information is available at the end of the article
}

It has been determined that despite the complex causes of the novel S-O 2009 IV epidemic, airborne spread was one of the major reasons for the pandemic [7]. Aerosols are solid or liquid suspensions in the air and their particle size range is $0.001-100 \mu \mathrm{m}$ [8]. Once formed, aerosols, including those containing viruses, can rapidly spread to a larger area with the assistance of the wind [9]. However, little is known about the transmission and infection of the novel S-O 2009 IV via aerosols, and there is still some debate about airborne infection of this virus $[7,8,10,11]$.

In early January 2011, a local animal disease prevention and control center in Shandong, China reported that a pig farm in eastern China emerged the suspected novel S-O 2009 IV disease. More importantly, similar infections occurred successively in some downwind pig farms within a week, and workers of these pig farms developed flu-like symptoms. Isolation and identification of pathogens confirmed S-O 2009 IV infection. Thus, we 
speculated that airborne transmission played an important role in the spread of this epidemic. Here, we collected indoor air, pig nasopharyngeal swabs, and blood samples to analyze the positive rate of the S-O 2009 IV; and based on both pig and guinea pig aerosol infection models, airborne infection capacity of S-O 2009 IV isolate was evaluated.

\section{Results}

\section{Identification of viruses}

The seven viral isolates were obtained from the nasopharyngeal swab samples, including three strains of H1N1 and four strains of H3N2. Antigenicity and sequence analysis of the three strains of H1N1 viruses confirmed that the isolated strain was S-O 2009 IV. And the isolate (A/swine/Shandong/07/2011) was used in aerosol infection models to verify its airborne transmission traits.

\section{Results of air and serum samples}

The positive rate of 157 air samples collected from the 40 pig farms was $26.1 \%$ (41/157) and the virus content range was $4.09-5.72 \log _{10}$ copies $/ \mathrm{m}^{3}$ air; hemagglutination and hemagglutination-inhibition (HA-HI) tests showed that the positive rate of serum samples was $28.5 \%(57 / 200)$ and titers were $80-2560$. Infection analysis of staff with flu-like symptoms from seven pig farms found that $43.5 \%(10 / 23)$ were seropositive rate for S-O 2009 IV infection (from CDC) (Table 1).

\section{Results of S-O 2009 IV aerosol infection models}

All experimental pigs and guinea pigs in the challenged groups were shown to shed viruses and seroconverted to S-O 2009 IV. In the swine infection model experiments, viruses were detected in the direct contact groups from nasal secretions of three pigs during the first round of experiment and two pigs during the second round. In the aerosol infection group, two pigs were positive during the first round of experiments and one positive during the second round. Pigs with virus detected in nasal secretions were also positive by serological testing. Serum titers of the direct contact group and aerosol infection group were $320-1280$ and $640-1280$, respectively (Table 2).

In the guinea pig infection model experiments, viruses were detected in nasal secretions from four guinea pigs in the first round of experiments and three guinea pigs in the second round in the direct contact group. In the aerosol infection group, viruses were detected in nasal secretions from two guinea pigs for the first round of experiments and three guinea pigs for the second round. Serum titers of animals in the direct contact group and aerosol infection group were $320-1280$ and 320-1280, respectively (Table 2).

Table 1 Detection results of airborne S-O 2009 IV in 40 pig farms

\begin{tabular}{|c|c|c|c|c|c|c|c|}
\hline Farms & Air samples & $\begin{array}{l}\text { Virus RNA copies of } \\
\text { air samples }\left(\log _{10} / \mathrm{m}^{3}\right)\end{array}$ & Sero- Conversion & Farms & Air samples & $\begin{array}{l}\text { Virus RNA copies } \\
\text { of air samples }\left(\log _{10} / \mathrm{m}^{3}\right)\end{array}$ & Sero- Conversion \\
\hline Farm 1 & $4 / 6$ & 4. $14-5.62$ & $3 / 5$ & Farm 21 & $3 / 6$ & $4.41-5.07$ & $3 / 5$ \\
\hline Farm 2 & $4 / 6$ & $4.05-4.93$ & $5 / 5$ & Farm 22 & $0 / 4$ & 0 & $0 / 5$ \\
\hline Farm 3 & $2 / 5$ & $3.83 / 5.66$ & $4 / 5$ & Farm 23 & $1 / 4$ & 4.62 & $2 / 5$ \\
\hline Farm 4 & $2 / 4$ & $4.20 / 4.54$ & $3 / 5$ & Farm 24 & $1 / 4$ & 4.40 & $2 / 5$ \\
\hline Farm 5 & $2 / 4$ & 4.75/5. 19 & $2 / 5$ & Farm 25 & $1 / 3$ & 4.78 & $1 / 5$ \\
\hline Farm 6 & $2 / 4$ & $3.74 / 4.64$ & $4 / 5$ & Farm 26 & $1 / 4$ & 3.14 & $2 / 5$ \\
\hline Farm 7 & $3 / 4$ & $4.20-4.63$ & $3 / 5$ & Farm 27 & $0 / 4$ & 0 & $0 / 5$ \\
\hline Farm 8 & $3 / 4$ & $4.12-5.72$ & $4 / 5$ & Farm 28 & $0 / 3$ & 0 & $0 / 5$ \\
\hline Farm 9 & $3 / 4$ & $4.55-5.09$ & $3 / 5$ & Farm 29 & $0 / 3$ & 0 & $0 / 5$ \\
\hline Farm10 & $0 / 4$ & 0 & $1 / 5$ & Farm 30 & $0 / 3$ & 0 & $1 / 5$ \\
\hline Farm 11 & $0 / 3$ & 0 & $0 / 5$ & Farm 31 & $0 / 3$ & 0 & $0 / 5$ \\
\hline Farm12 & $0 / 3$ & 0 & $0 / 5$ & Farm 32 & $0 / 3$ & 0 & $0 / 5$ \\
\hline Farm13 & $0 / 4$ & 0 & $0 / 5$ & Farm33 & $1 / 4$ & 4.95 & $3 / 5$ \\
\hline Farm14 & $0 / 4$ & 0 & $0 / 5$ & Farm34 & $0 / 4$ & 0 & $0 / 5$ \\
\hline Farm15 & $1 / 3$ & 5.50 & $0 / 5$ & Farm35 & $0 / 3$ & 0 & $1 / 5$ \\
\hline Farm16 & $0 / 4$ & 0 & $0 / 5$ & Farm 36 & $0 / 4$ & 0 & $0 / 5$ \\
\hline Farm17 & $2 / 4$ & $4.42 / 5.02$ & $1 / 5$ & Farm 37 & $0 / 3$ & 0 & $0 / 5$ \\
\hline Farm18 & $1 / 5$ & 5.59 & $1 / 5$ & Farm 38 & $1 / 4$ & 4.65 & $3 / 5$ \\
\hline Farm19 & $3 / 4$ & 4. $91-5.33$ & $4 / 5$ & Farm 39 & $0 / 4$ & 0 & $0 / 5$ \\
\hline Farm20 & $0 / 4$ & 0 & $0 / 5$ & Farm 40 & $0 / 4$ & 0 & $1 / 5$ \\
\hline
\end{tabular}


Table 2 Transmission and infection of 2009 A(H1N1) IV aerosol in pig model and guinea pig model

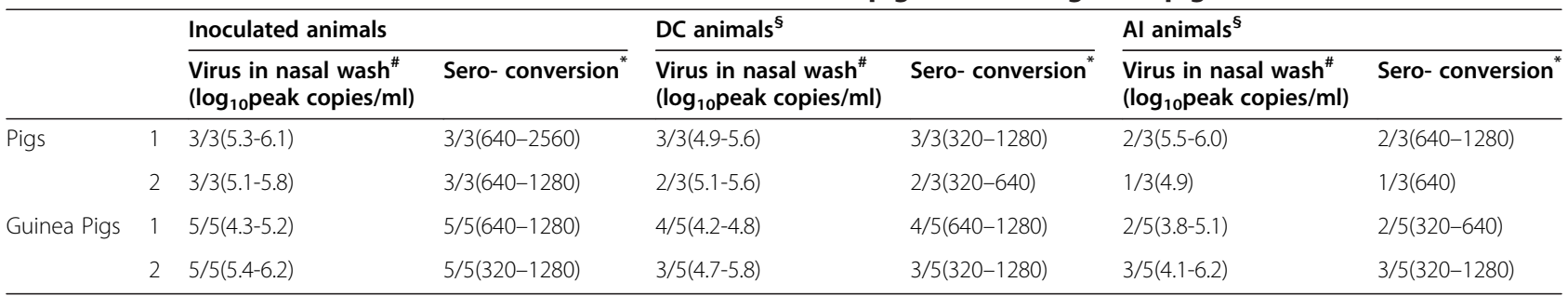

${ }^{5} \mathrm{DC}$ direct contact; Al aerosol infection; ${ }^{*}$ Virus titers are expressed as mean $\log _{10}$ peak copies/ml; ${ }^{*}$ Hemagglutination inhibition(HI)assay was performed with homologous virus and turkey red blood cells. No. of positive animals and $\mathrm{HI}$ range indicated.
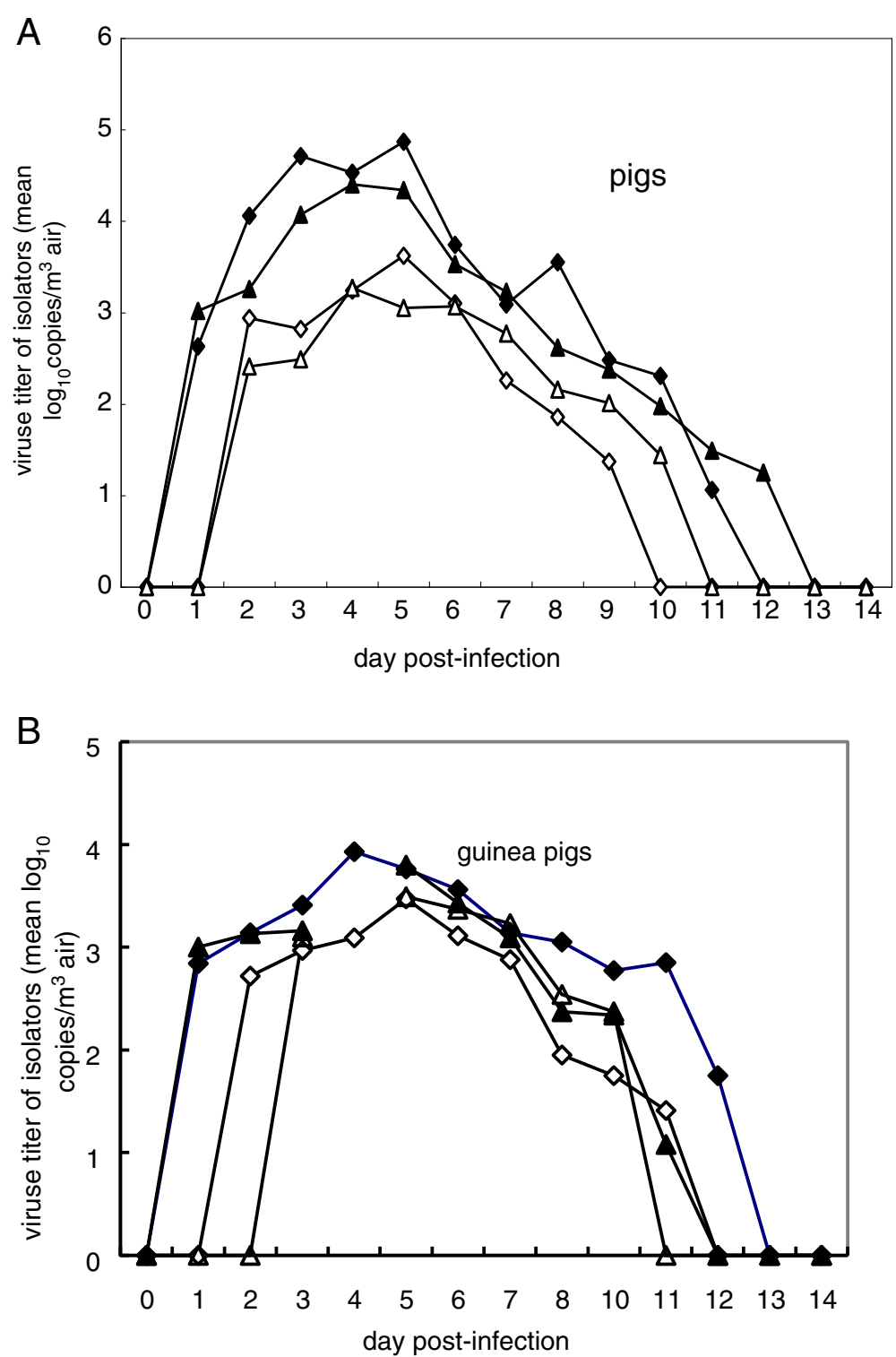

$\longrightarrow$ IsolatorA $\longrightarrow$ Isolator B Isolator A $\rightarrow \triangle$ Isolator B

Figure 1 Concentration of the SO 2009(H1N1)IV aerosol produced by pigs and guinea pigs in isolators A and B. The diamond represents the first round of experiment; triangle represents the second. Black represents isolator A, white represents isolator B. (B) Not detected in the first round of experiment 4dpi Day 0: animals in group A w ere intranasally inoculated with $10^{6} \mathrm{pfu}$ of the novel influenza A (H1N1) virus. 


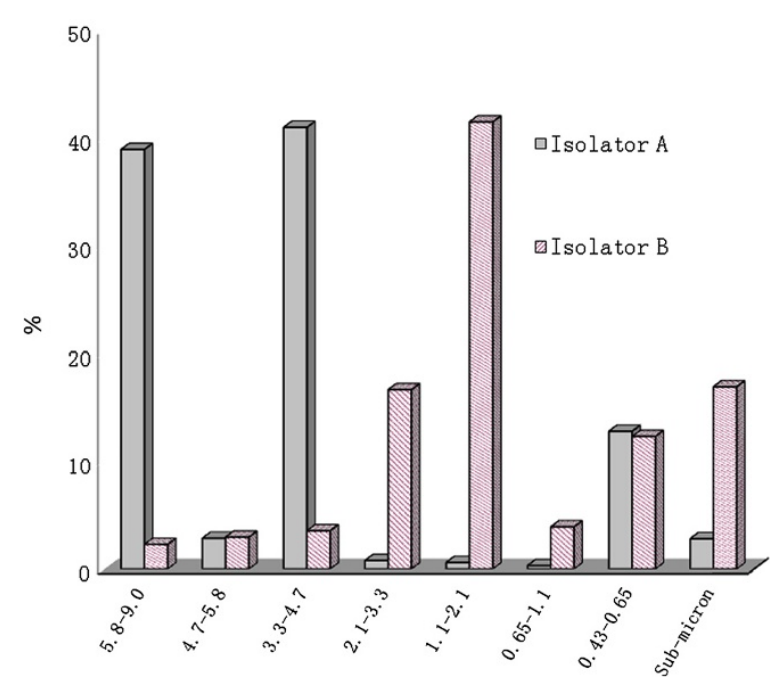

Figure 2 Distribution characteristics of the novel influenza $A$ (H1N1) virus from isolator $A$ and $B$ on the Andersen-8-stage impactor, Based on RT-qPCR results. X-axis: aerodynamic diameter of airborne viral particles on Andersen-8 sampler (from left to right:1-8 stage); Y-axis: the distribution percentage of viral particles on every stage of Andersen-8 sampler.

During the two rounds of swine infection model experiments, S-O 2009 IV aerosols were detected at the beginning of 1 day post-infection (dpi) in isolator $\mathrm{A}$, peaked $\left(4.87,4.40 \log _{10}\right.$ copies $/ \mathrm{m}^{3}$ air) at 5 and $4 \mathrm{dpi}$, and was absent from 12 or $13 \mathrm{dpi}$. In isolator $\mathrm{B}, \mathrm{S}-\mathrm{O}$ 2009 IV aerosols were detected at $2 \mathrm{dpi}$, peaked (3.62, $3.27 \log _{10}$ copies $/ \mathrm{m}^{3}$ air) at 5 and $4 \mathrm{dpi}$, and was absent after 10 or 11 dpi (Figure $1 \mathrm{~A})$.

For the guinea pig experimental infection model, the results of the two rounds of experiments indicated that virus shedding was detected at $1 \mathrm{dpi}$ of the challenged group; S-O 2009 IV aerosols were detected at 1 and 2 dpi, peaked at 4 and $5 \mathrm{dpi}$ (in isolator $\mathrm{A}$ and in isolator B) and disappeared at 11-13 dpi. In the two rounds of guinea pig infection model experiments, S-O 2009 IV aerosols were detected at $1 \mathrm{dpi}$ in isolator $\mathrm{A}$, peaked at 4 and $5 \mathrm{dpi}\left(3.93,3.80 \log _{10}\right.$ copies $/ \mathrm{m}^{3}$ air), and was absent from 12-13 dpi. In isolator B, SO 2009 IV aerosols were detected at post-inoculation 2 and 3 days, peaked at 5 dpi (3.47, $3.49 \log _{10}$ copies $/ \mathrm{m}^{3}$ air), and was absent at 11 or $12 \mathrm{dpi}$ (Figure 1B).

\section{Diameter of S-O 2009 IV aerosol particles}

In isolator $\mathrm{A}$, the distribution ratio of viral aerosol particle sizes was highest for a particle diameter of 3.3-4.7 $\mu \mathrm{m}(40.95 \%)$, and lowest for $0.65-1.1 \mu \mathrm{m}(0.30 \%)$. In isolator $\mathrm{B}$, the distribution ratio of viral aerosol particle sizes was highest for particle diameters of 1.1-2.1 $\mu \mathrm{m}$ (41.45\%), and lowest for 5.8-9.0 $\mu \mathrm{m}$ (2.28\%) (Figure 2).

\section{Discussion}

Since early January 2011, the S-O 2009 IV epidemic was first identified in two pig farms of eastern China that quickly spread to nearly 20 farms within a week. A geographical analysis of these pig farms showed that these farms were distributed in a close ellipsoid zone with a central axis in line with prevailing northwesterly winds. A collection of 157 air samples from 40 pig farms revealed that $26.1 \%$ contained virus with almost $50 \%$ of pig farms in the area affected. This transmission was presumed to be via downwind dissemination of S-O 2009 IV aerosols. It appears that the virus was spread by airborne transmission and our findings in experimental models support this.

During the experiments, pigs and guinea pigs were housed in positive- and negative-pressure isolators, effectively avoiding the contamination with exogenous microbes. Aerosol transmission experiments were conducted so that the air in isolator B came exclusively from isolator A, which were connected using a $2 \mathrm{~m}$ closed tube. Therefore, any infection in isolator B would be determined as aerosols (Figure 3).

During the experimental infections in pigs, S-O 2009 IV was detected at 1-2 dpi in isolators A and B, and the maximum amount of virus detected in $\mathrm{A}$ and $\mathrm{B}$ were and 4.40-4.87 $\log _{10}$ copies/m3 air and 3.27-3.62 $\log 10$ copies/m3 air, at 4 and $5 \mathrm{dpi}$, respectively. However, during the two rounds of experiments, the amounts of virus detected were consistently lower in B than in A and virus was not detectable at 12-13 dpi in A and at 10-11 dpi in B. The duration of detectable S-O 2009 IV aerosols in isolator $\mathrm{B}$ was shorter and the amounts of virus were lower than those in isolator $\mathrm{A}$, which was likely related with the deposition, survival time, and removal of aerosol particles.

There is a $2 \mathrm{~m}$ pipe between the two isolators (upper distal end, 5.3m from the challenged group; Figure 4); therefore, infection in isolator B occurred not via droplet but by aerosolized virus particles. Meanwhile the certain wind velocity in the pipe can well simulate natural wind between different pig farms, even between different pig houses in the same farm. Additionally, aerosol infection group and direct contact group were both serologically positive and nasal secretions had evidence of virus shedding. Nonetheless, the number of infections in aerosol infection group was smaller than in direct contact group, there was no difference in the extent of virus shedding and serum titers of infected pigs. These data demonstrated that infection with these viral strains can induce airborne infection.

Our data indicated that infected pigs located in upwind farms can generate viruses in nasal and respiratory secretions and spread via the wind to downwind farms. Thus, this type of transmission is dependent on weather, where changes in wind force, wind direction, ultraviolet 


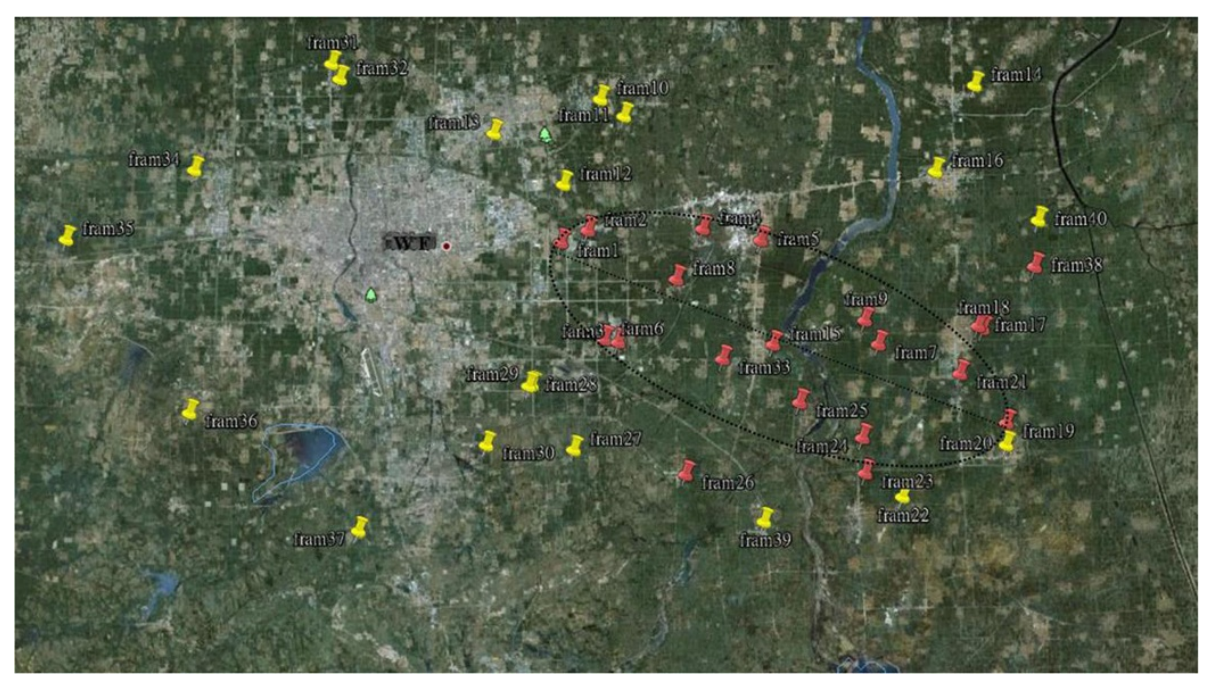

Figure 3 The map is the part of East China area, red points represent the positive pig farms, and yellow ones represent the negative pig farms.

light, temperature or humidity are all likely to affect transmission.

Since the respiratory tract of guinea pigs is very similar to that of humans, guinea pigs were regarded as an appropriate mammalian model for use in this study [12]. In the two repeated trials on guinea pigs, the rates of virus detection and seroconversion to the S-O 2009 IV in aerosol infection group were $2 / 5$ and $3 / 5$ (Table 2), indicating that aerosol infection group was infected by viral aerosols in isolator A and the virus had the capability of airborne transmission among mammals. Therefore, it can be inferred that S-O 2009 IV is likely to be a health risk for farm staff and may be an important point for the prevention and control of new zoonoses, especially swine influenza viruses. It has been reported that the S-O 2009 IV is still persistent among pigs in China and thus remains a major threat to human health $[13,14]$.

At 4 and $5 \mathrm{dpi}$, the virus content in air samples reached its peak in the isolator along with the amount of virus in nasal secretions and the number of pigs infected in different groups. These data indicated that the amount of virus contained in aerosols is related to the virus shedding capacity and number of infected animals. Until 11-13 dpi, no airborne S-O 2009 IV was detected in the two isolators. Correspondingly, animals in all the experimental groups no longer shed virus. These results suggest that the viruses produced in nasal secretions by animals formed aerosols.

Although the detectable time and concentrations of airborne virus in the two animal experiments were different, the viral aerosol concentration increased or decreased coincidentally. In addition, the viral aerosol concentration was affected by the ventilation rate and the number of infected animals.
The aerodynamic diameter ranges of aerosols in isolator A were determined to be 3.3-4.7 $\mu \mathrm{m}$ and 5.8-9.0 $\mu \mathrm{m}$; however, in isolator B particle size was typically 1.1-2.1 $\mu \mathrm{m}$. The loss of large particle droplets was mainly due to sedimentation, and the loss of aerosol particles $<5 \mu \mathrm{m}$ was mainly due to the inactivation of virus particles and ventilation [15], indicating that smaller particles gathered in isolator B under the effect of ventilation. In the two isolators, particles were typically $\leq 4.7 \mu \mathrm{m}$, showing that a higher proportion of viral aerosols can enter the lower respiratory tract via the nasal cavity, whereas particles $\leq 1 \mu \mathrm{m}$ can enter bronchioles and alveoli, and deposit in the alveoli, increasing the risk of serious infection. Gustin et al. [16] indicated that when discharged by breathing or sneezing in ferrets, influenza virus particles were typically $\leq 4.7 \mu \mathrm{m}$. During the flu season, the less than $4 \mu \mathrm{m}$ (aerodynamic diameter) influenza viral aerosol particles accounted for $53 \%$ of the airborne influenza viral count in hospital environments [17-19], consistent with the experimental results of this study. In conclusion, animals infected with S-O 2009 IV can form aerosols that can lead to airborne transmission.

\section{Materials and methods}

\section{Outbreak of the epidemic and virus isolation and identification}

The swine flu epidemic occurred in eastern China $\left(119^{\circ} \mathrm{E}\right.$, $\left.36.30^{\circ} \mathrm{N}\right)$, a warm temperate semi-humid monsoon climate zone, with cold, dry winters dominated by northwesterly winds [20]. In early January 2011, a suspected new swine flu epidemic suddenly emerged in a few pig farms of this region and within a week similar epidemics emerged successively in some pig farms in the downwind 


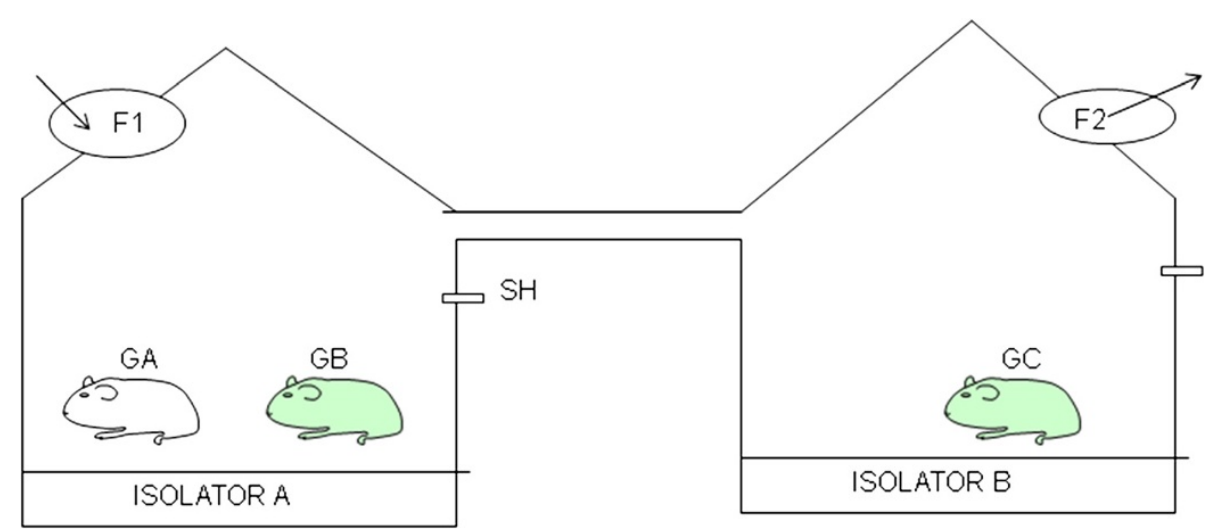

Figure 4 Arrangement of the isolators applicable to pigs and guinea pigs. Animals in inoculation group (GA) and direct contact group (GB) were housed in the isolator $\mathrm{A}$, and animals in aerosol infection group (GC) were housed in the isolator $\mathrm{B}$. The two isolators were connected with a tube $(2 \mathrm{~m})$ which allowed the air flowed from A to B. SH is a sampling hole from which air samples were collected. F1 is a positive pressure fan and F2 is a negative fan. The air flowing through the two fans was filtered to remove microorganisms.

direction of this pig farm (Figure 3). A total of 120 nasopharyngeal swabs taken from infected pigs were collected for virus isolation and identification, as previously described by Cong et al. [21]. Samples were processed in a BSL -2+ laboratory.

\section{Collection and process of air, nasopharyngeal swab and blood samples}

A total of 157 air samples were collected using AGI-30 (All Glass Impinger) placed in the middle of the pig farm, at $1.5 \mathrm{~m}$ from the ground, using $20 \mathrm{~mL}$ phosphate buffered saline (PBS) sampling medium, with a flow velocity of $12.5 \mathrm{~L} / \mathrm{min}$ for $40 \mathrm{~min}$ [22,23]. Virus was detected in samples using the RT-qPCR methods [24]. Serum samples from pigs $(\mathrm{n}=200)$ and pig farm staff $(\mathrm{n}=23)$ displaying flu-like symptoms were collected and processed by the local centers for disease control (CDC) [25].

\section{Establishment of S-O 2009 IV aerosols transmission and infection models}

Weaned piglets $(8-10 \mathrm{~kg})$ and guinea pigs $(250-300 \mathrm{~g})$ seronegative for S-O 2009 IV were purchased from the Shandong Taibang Biological Product Co., Ltd. And used for experimental infections. All prevailing local, national and international regulations and conventions, and normal scientific ethical practices have been respected in this study. Two positive- and negative-pressure isolators A and B (Model C.C.JH-1; Tianjin Jinhang Purified Air Conditioning Engineering Company, China) were connected using a closed tube $2 \mathrm{~m}$ in length and $8 \mathrm{~cm}$ in diameter, to adjust air flow from A to B, which not only prevented direct contact of animals in the aerosol infection group with those in the inoculation group, but also prevented the propagation of droplets (Figure 4). Three pigs or five guinea pigs were intranasally inoculated with $10^{6}$ plaque-forming units (PFU) of viruses were placed in isolator $\mathrm{A}$, and were designated inoculation group. After $24 \mathrm{~h}$, another three pigs or five guinea pigs were placed into isolator $\mathrm{A}$, and were designated direct contact group. Three pigs or five guinea pigs were placed into isolator $\mathrm{B}$, and were designated aerosol infection group [26,27]. The isolator temperature was maintained at $20 \pm 1{ }^{\circ} \mathrm{C}, 30 \pm 4 \%$ relative humidity $(\mathrm{RH})$, and $0.05-0.2 \mathrm{~m} / \mathrm{s}$ wind velocity [28]. Pig and guinea pig experiments were conducted independently and repeated. "The Society for Animal Health Feedings \& Animal Welfare of Shandong Province approved the study of "Airbone spread and infection of a novel swineorigin influenza $\mathrm{A}(\mathrm{H} 1 \mathrm{~N} 1)$ virus" and agreed to exam the serum samples from 200 pigs and 23 pig farm staff for the experiments of that.

\section{Collection of aerosols, nasal washes, and blood in infection experiments}

After sequencing and analysis of eight fragments from several virulent strains, three strains were identified as the S-O 2009 IV and one of them was used for the aerosol dissemination experiment. Virus shedding and serum antibodies of nasal secretions in experimental animals were monitored and detected to verify if the experimental animals were infected. Nasal secretions from each animal were collected every other day after virus inoculation and after RNA extraction, virus nucleic acids were detected by RT-qPCR [29]. At 7 and $14 \mathrm{dpi}$, blood from each experiment animal was collected to test for specific antibodies [30].

After inoculation, the AGI-30 air collection device was used to collect air samples in isolators A and B on each day [26] and the virus content in samples was detected using RT-qPCR. To determine the proportion and distribution of aerosol particles of different sizes, at $4 \mathrm{dpi}$ of 
the second round of the guinea pig model experiments, the Andersen-8-level collector [18] was used to collect aerosolized viral particles in isolators $\mathrm{A}$ and $\mathrm{B}$, using a sterile1\% gelatin glycerol (1\% gelatin PBS and glycerol $1: 1$ mixed) as the medium, at $28.3 \mathrm{~L} / \mathrm{min}$ flow velocity for $40 \mathrm{~min}$, and the virus content of every level was detected by RT-qPCR.

\section{Competing interests}

The authors declare they have no competing financial interests.

\section{Authors' contributions}

$H Z$ and $X L$ are contributed equally to this work. $R M, X L, Y Z, J G, H Y, Z M$ to participate in the writing of this paper. $H D, X L, Q L, M Z, Z L, B W, M C, H W$ and $\mathrm{PH}$ participate in the operation of the experiment. All authors read and approved the final manuscript.

\section{Acknowledgments}

We would like to express our sincere gratitude to Professor Liu Jinhua from China Agricultural University and the Tai'an Center for Disease Control for their contributions to this study. This work was supported by Chinese International Cooperation Program [2009DFA32890] and the open fund 2011 of the State Key Laboratory for Environmental Protection, Using of Environmental Microbiology and Security Controls and the National Natural Science Foundation of China for Youths (81101307).

\section{Author details}

${ }^{1}$ College of Animal Science and Veterinary Medicine, Shandong Agricultural University, Daizong Street 61, Tai'an 271018, China. ${ }^{2}$ Sino-German Cooperative Research Centre for Zoonosis of Animal Origin Shandong Province, Tai'an, Shandong, China. ${ }^{3}$ Key Laboratory of Animal Biotechnology and Disease Control and Prevention of Shandong Province, Tai'an, Shandong, China. ${ }^{4}$ Affiliated Hospital of the Shandong Agricultural University, Tai'an, China. ${ }^{5}$ Taishan Medical University, Tai'an, China. ${ }^{6}$ Centre for Disease Control, Tai'an, the People's Republic of China, Tai'an, China. ${ }^{7}$ The Animal Husbandry Bureau of Tai'an City, Tai'an, China.

Received: 5 January 2013 Accepted: 7 May 2013

Published: 22 June 2013

\section{References}

1. Zepeda-Lopez HM, Perea-Araujol L, Miliar-Garca1 A, Dominguez-Lopez A, Xoconostle-Cazarez B, Lara-Padilla E: Inside the outbreak of the 2009 influenza A(H1N1)v virus in Mexico. PLoS One 2010, 5:e13256.

2. Novel swine-origin influenza $A(\mathrm{H} 1 \mathrm{~N} 1)$ virus investigation team: Emergence of a novel swine-origin influenza $\mathrm{A}(\mathrm{H} 1 \mathrm{~N} 1)$ virus in humans. $N$ Engl J Med 2009, 360:2605-2615.

3. Seema J, Laurie K, Anna MB, Ann MS, Stephen RB, Janice L: Hospitalized patients with 2009 H1N1 influenza in the United States, April-June 2009. N Engl J Med 2009, 361:1935-1944.

4. Jonathan RK: Swine influenza. J Clin Pathol 2009, 62:577-578.

5. Vincent $J M$, de Emmie $W$, van den Judith MA, van den B, Sander $H$, Eefje JAS, Theo MB: Pathogenesis and transmission of swine-origin $2009 \mathrm{~A}$ (H1N1) influenza virus in ferrets. Science 2009, 325:481-483.

6. Wang HJ: Update of influenza A [H1N1]. Jilin Medicine 2011, 32:133-135.

7. Maines TR, Jayaraman A, Belser JA, Wadford DA, Pappas C, Zeng H: Transmission and pathogenesis of swine-origin 2009 A(H1N1) influenza viruses in ferrets and mice. Science 2009, 325(5939):484-487.

8. Tellier R: Aerosol transmission of influenza A virus: a review of new studies. J R Soc Interface 2009, 6:S783-S790.

9. Xihua $Y$ : The infection and control of microoganism aerosol-concurrently treats of prevent in the SARS virus. Contamination Control \& Air-Conditioning Technology 2003, 4:25-29.

10. Wit E, Vincent JM, Riel D, Walter EPB, Rimmelzwaan GF, Kuiken T: Molecular determinants of adaptation of highly pathogenic avian influenza H7N7 viruses to efficient replication in the human host. J Virol 2010, 84:1597-1606

11. Piso RJ, Albrecht $Y$, Handschin P, Bassett S: Low transmission rate of 2009 H1N1 influenza duringa long-distance bus trip. Infection 2011, 39:149-153.
12. Sun $Y P, B i$ YH, Pu J, Hu YX, Wang JJ, Gao HJ: Guinea pig model for evaluating the potential public health risk of swine and avian influenza viruses. PLoS One 2010, 5:e15537.

13. Howden KJ, Brockhoff EJ, Caya FD, Mclecod LJ, Lavoie M, Ing JD: An investigation into human pandemic influenza virus (H1N1)2009 on an Albeta swine farm. Can Vet J 2009, 50:p1153-p1161.

14. Zhao G, Pan JJ, Gu XB, Lu XL, Li QH, Hu J: Isolation and phylogenetic analysis of avian-origin European H1N1 swine influenza viruses in Jiangsu China. Virus Genes 2011, 44:11.

15. Yang W, Marr LC: Dynamics of airborne influenza A viruses indoors and dependence on humidity. PLoS One 2011, 6:e21481.

16. Gustin KM, Belser JA, Wadford DA, Pearce MB, Katz JM, Tumpey TM: Influenza virus aerosol exposure and analytical system for ferrets. PNAS 2011, 108:8432-8437

17. Blachere FM, Lindsley WG, Pearce TA, Anderson SE, Fisher M, Khakoo R: Measurement of airborne influenza virus in a hospital emergency department. Clin Infect Dis 2009, 48:438-440.

18. Andersen AA: New sampler for the collection, sizing, and enumeration of viable airborne particles. J Bacterial 1958, 76:471-484.

19. Chai TJ, Ma RH, Mueller W, Wang HR: Study on microbiological floras in air of supplying materials workshop in a biological refuse treatment Plant. $J$ Environ Health 2000, 6:358-363.

20. Zhang J, Yang WZ, Guo YJ, Xu H, Zhang Y, Li Z: Epidemiologic characteristics of influenza in China from 2001 to 2003. Chin J Epidemiol 2004, 25:461-465.

21. Cong YL, Pu J, Liu QF, Wang S, Zhang GZ, Zhang XL: Antigenic and genetic characterization of H9N2 swine influenza viruses in China. J Gen Virol 2007, 88:2035-2041.

22. Brachman PS, Ehrlich R, Eichenwald HF, Gabelli VJ, Kethley TW, Madin SH: Standard sampler for assay of airborne microorganisms. Science 1964, 144:1295.

23. Chapin A, Rule A, Gibson K, Buckley T, Schwab K: Airborne multidrugresistant bacteria isolated from a concentrated swine feeding operation. Environ Health Perspect 2005, 113:137-142.

24. Poon LL, Chan KH, Smith GJ, Leung CSW, Guan Y, Yuen KY: Molecula detection of a novel human influenza (H1N1) of pandemic potentia by conventional and real-time quantitative RT-PCR assays. Clin Chem 2009, 55:1555-1558

25. Luo XS, Li KM, Huang JD, Lin JR, Li JX: Seroprevalence of swine influenza H1N1 virus. C J Vet Med 2011, 47:39-40.

26. Yao ML, Zhang XX, Gao J, Chai TJ, Miao ZM, Ma W: The occurrence and transmission characteristic of airborne H9N2 avian influenza virus. Berl Munch Tieraerztl Wochschr 2011, 124:10-15.

27. Li XX, Chai TJ, Wang ZL, Song CP, Cao HJ, Liu JB: Occurrence and transmission of Newcastle disease virus aerosol originating from infected chickens under experimental conditions. Vet Microbiol 2009, 136:226-232.

28. Lowen AC, Steel J, Mubareka S, Palese P: High temperature $\left(30^{\circ} \mathrm{C}\right)$ blocks aerosol but not contact transmission of influenza virus. J Virol 2008, 82:5650-5652.

29. Lowen AC, Mubareka S, Tumpey TM, García-Sastre A, Palese P: The guinea pig as a transmission model for human influenza viruses. PNAS 2006, 103(26):9988-9992.

30. Yao HC: Experiment guidance for veterinarian microbiology. 25th edition. Beijing: China Agriculture Press; 2007:105-107.

doi:10.1186/1743-422X-10-204

Cite this article as: Zhang et al:: Airborne spread and infection of a novel swine-origin influenza A (H1N1) virus. Virology Journal 2013 10:204. 